Ann. Zootech., 1977, 26 (4), 471-479.

I.N.R.A.

BIBLIOTHEQUE UO 3593 ?

DOMAINE OE CROUELL:

CLERMONT-FD CEDEX?

\title{
Valeur alimentaire chez le Mouton de l'ensilage de marc de raisin épuisé
}

\author{
Y. REYNE et X. GARAMBOIS
}

avec la collaboration technique de D. FABRE et J. I. GAUBERT

Station de Physiologie animale I.N.R.A.

E.N.S.A., Place Viala

34060 Montpellier Cedex (France)

\section{Résumé}

La digestibilité des constituants de divers échantillons de marc de raisin épuisé entier et les quantités ingérées ont été mesurées sur des lots de 6 moutons Mérinos d'Arles adultes maintenus en cages à métabolisme. Le marc vapeur est le mieux utilisé, mais les coefficients de digestibilité sont cependant très faibles, soit, selon les échantillons : 25 à 28 p. I oo pour la matière organique, I6 à $26 \mathrm{p}$. Ioo pour la cellulose brute, 8 à I 3 p. Ioo pour les matières azotées, $4^{8}$ p. Ioo pour les matières grasses.

Les animaux sont capables d'ingérer des quantités considérables de matière sèche, de l'ordre de I Io $\mathrm{g}$ par $\mathrm{kg}$ de poids métabolique $\left(p^{0,75}\right)$ avec le marc vapeur seul. Par contre, le marc diffusion n'a pas permis une ingestibilité aussi forte et les animaux ont perdu du poids.

L'addition d'une quantité d'environ $600 \mathrm{~g}$ de foin de luzerne au marc vapeur distribué ad libitum a entraîné une légère augmentation des coefficients de digestibilité du marc (+ 7 p. Ioo pour la cellulose brute, $+I_{4} \mathrm{p}$. Ioo pour les matières grasses), sauf pour les matières azotées. La consommation totale de matière sèche est également augmentée de I 4,5 p. I oo par rapport à celle mesurée pour la ration marc seul et de $55,5 \mathrm{p}$. I oo par rapport à celle mesurée pour la ration foin de luzerne seul.

\section{Introduction}

Depuis de nombreuses années, le marc de raisin ensilé a été utilisé de manière plus ou moins régulière comme fourrage d'appoint ou de secours par les éleveurs de moutons des régions méditerranéennes. Les références dont on dispose sur la valeur nutritive de ce type de produit (DEchambre, I906; FABRE, I9o9; HoNCAMP et BLANCK, I9I9; JORE D'ARCE, I953; PICCIONI, I965) indiquent notamment une très faible digestibilité de la matière sèche (environ $30 \mathrm{p}$. Ioo). La digestibilité des matières azotées est encore plus faible et semble plus variable $(6$ à $20 \mathrm{p}$. roo selon les marcs étudiés). 
La composition chimique et la valeur nutritive des marcs de raisin dépendent de nombreux facteurs parmi lesquels il faut citer : le cépage, le rendement, le mode de vinification, le procédé de distillation, les proportions de rafles, pellicules et pépins, le mode de conservation.

A l'heure actuelle, les marcs de raisins les plus fréquemment disponibles sous forme humide sont les marcs épuisés entiers, c'est-à-dire des marcs contenant pépins, pulpes et rafles et ayant subi la distillation. Schématiquement, sur le plan technologique, les marcs sont épuisés selon deux procédés permettant d'extraire l'alcool et les éléments fermentescibles : extraction à la vapeur (marc vapeur) ou lessivage à l'eau (marc diffusion). En fonction des circonstances climatiques, les éleveurs se posent périodiquement le problème de l'utilisation de ce type de produit. Il convenait donc de préciser davantage sa valeur alimentaire (digestibilité, quantités ingérées) en particulier lorsqu'il est associé à d'autres fourrages dans la ration et compte tenu du fait que son acceptabilité par le Mouton apparaît extrêmement variable selon le mode de distillation.

\section{Matériel et méthodes}

- Dans un premier essai, nous avons étudié la digestibilité et les quantités ingérées par des ovins pour deux échantillons de marc de raisin (un échantillon de marc vapeur - un échantillon de marc diffusion) utilisés comme seul constituant de la ration.

Les mesures de digestibilité ont été réalisées selon un protocole analogue à celui de Demarquili y et Weiss (I970) dans leur étude de la valeur alimentaire des fourrages. Nous avons utilisé des lots de 4 moutons Mérinos d'Arles adultes maintenus en cages à métabolisme; deux autres animaux en cases individuelles permettaient de mesurer les quantités ingérées sur 6 animaux. Le marc de raisin était distribué ad libitum en deux repas journaliers, les refus n'excédant pas Io p.Ioo de la quantité distribuée. La période d'adaptation au régime était de ${ }_{5} 5$ jours et était suivie de deux périodes de mesure d'une semaine chacune, soit I5 jours de contrôle ( 8 données par aliment). Nous avons calculé les coefficients de digestibilité apparents de la matière organique, des matières azotées et de la cellulose brute.

- Dans un deuxième essai, nous avons mesuré successivement et avec les mêmes animaux la digestibilité d'un bon foin de luzerne, celle d'un nouvel échantillon de marc vapeur, puis celle de la ration marc vapeur ad libitum plus une quantité constante de $600 \mathrm{~g}$ du foin de luzerne précédemment étudié. Les périodes de transition entre les divers régimes étaient de 3 semaines et les périodes de mesure de la digestibilité duraient 7 jours (4 données par aliment). Les coefficients de digestibilité apparents de la matière organique, des matières azotées, de la cellulose brute et des matières grasses ont été calculés pour les différentes rations. Dans le cas de la ration marc plus foin, les coefficients de digestibilité du marc de raisin ont été estimés par différence en supposant qu'il n'y avait pas de phénomène de digestibilité associative.

- Les mares de raisin utilisés au cours des deux séries d'essais étaient ensilés dans des fûts en matière plastique de I5o litres hermétiquement clos. Ce procédé nous a permis de disposer continuellement d'un produit bien conservé. Un condi- 
ment minéral vitaminisé adapté était mélangé chaque jour à la ration à raison de 20 à $30 \mathrm{~g}$ par animal. Le tableau I donne la composition chimique des différents aliments utilisés au cours des deux séries d'essais. I.es marcs étudiés ont une composition chimique très voisine de celle des marcs le plus souvent produits dans la région Languedoc-Roussillon et analysés par le Service interdépartemental d'Élevage (I975).

TABLEAU I

Composition chimique des difévents aliments utilisés

Chemical composition of the different feedstuffs

\begin{tabular}{|c|c|c|c|c|}
\hline \multirow{2}{*}{$\begin{array}{l}\text { Nature de l'aliment } \\
\text { Type of feedstuff }\end{array}$} & \multicolumn{2}{|c|}{$\begin{array}{l}\text { ESSAI I } \\
\text { TrIaL I }\end{array}$} & \multicolumn{2}{|c|}{$\begin{array}{l}\text { ESSAI } 2 \\
\text { TRIAL } 2\end{array}$} \\
\hline & $\begin{array}{l}\text { Marc diffusion } \\
\text { Water washed } \\
\text { grape marc }\end{array}$ & $\begin{array}{l}\text { Marc vapeur } \\
\text { Steam washed } \\
\text { grape mavc }\end{array}$ & $\begin{array}{l}\text { Marc vapeur } \\
\text { Steam washed } \\
\text { grape mare }\end{array}$ & $\begin{array}{c}\text { Foin de luzerne } \\
\text { Lucerne hay }\end{array}$ \\
\hline $\begin{array}{l}\text { Matière sèche (p. Ioo). . } \\
\text { Dry matter (per cent) }\end{array}$ & $3^{2}, 7$ & 29,5 & 32,8 & 84,0 \\
\hline $\begin{array}{l}\text { Matières minérales }\left(^{*}\right) . \\
4 \sin \left({ }^{*}\right)\end{array}$ & 5,6 & 8,8 & 6,8 & 8,8 \\
\hline $\begin{array}{l}\text { Matières azotées totales }(*) \\
\text { Crude protein }\left(^{*}\right)\end{array}$ & I I ,9 & $13, \mathrm{I}$ & I $3, \mathrm{I}$ & I 6,8 \\
\hline $\begin{array}{l}\text { Cellulose brute }\left(^{*}\right) \\
\text { Crude fiber }\left(^{*}\right)\end{array}$ & 29,0 & 24,6 & 24,2 & $34, \mathrm{I}$ \\
\hline $\begin{array}{l}\text { Matières grasses }\left(^{*}\right) \cdot . \\
\text { Ether extract }\left({ }^{*}\right)\end{array}$ & - & - & 8,3 & 3,0 \\
\hline $\begin{array}{l}\text { Extractif non azoté }(*) \\
\text { Nitrogen-free exivact }(*)\end{array}$ & - & - & 47,6 & 37,3 \\
\hline
\end{tabular}

*) P. cent de la matière sèche.

(*) P. cent dry matter.

\section{Analyses}

- La teneur en matière sèche des aliments distribués, des refus et des fèces a été déterminée journalièrement par séchage à l'étuve à $80^{\circ} \mathrm{C}$ jusqu'à poids constant. Des échantillons représentatifs ont été constitués pour chaque période de mesure à partir de prélèvements journaliers des produits distribués, des refus et des fèces correspondantes. Ces échantillons ont été analysés pour déterminer leur teneur en matières minérales (calcination au four à $600^{\circ} \mathrm{C}$ ), en matières azotées (azote Kjeldahl $\times 6,25)$ et en cellulose brute (méthode de Weende). 


\title{
Résultats
}

\author{
Essai $I$
}

\section{Digestibilité}

L'utilisation digestive apparente des principaux constituants des deux échantillons de marc de raisin est très faible, surtout dans le cas du marc diffusion (tabl. 2). Pour ce dernier, on peut même considérer que la totalité des matières azotées est ir digestible; certains animaux ont d'ailleurs présenté des CUD négatifs, ce qui correspond probablement à une utilisation de leurs réserves.

\section{Ingestibilité}

Les quantités de matière sèche ingérées sont très importantes dans le cas du marc vapeur (tab1. 3) et permettent aux animaux d'en compenser la faible digestibilité puisqu'ils sont restés à poids constant durant toute la durée de l'essai. En ce qui concerne le marc diffusion, les quantités de matière sèche ingérées sont par contre très faibles et les animaux perdent du poids.

Que ce soit pour la digestibilité ou les quantités ingérées, les résultats sont beaucoup plus variables avec le marc diffusion.

\section{Essai $I I$}

\section{Digestibilité}

Bien que l'échantillon de marc vapeur utilisé ait une composition chimique très voisine de celle du premier échantillon, sa digestibilité lorsqu'il est distribué comme seul constituant de la ration est encore plus faible que précédemment. Seul le CUD des matières grasses est relativement élevé et voisin de $50 \mathrm{p}$. Ioo (tab1. 2). L'addition d'une quantité constante de foin de luzerne a pour effet d'augmenter, légèrement, chez tous les animaux en expérience la digestibilité de l'ensemble des constituants du marc étudié, particulièrement celle de la fraction cellulosique ( +7 p. IOo) et celle des matières grasses ( + I4 p. IOo). Par contre le CUD des matières azotées n'est pas modifié en moyenne. Par ailleurs, chez certains animaux, le marc de raisin a même pour effet de diminuer la digestibilité des matières azotées de la luzerne.

\section{Ingestibilité}

Pour la ration de marc seul, les quantités de matière sèche ingérées sont encore plus importantes qu'avec le marc vapeur précédemment étudié. L'addition du foin de luzerne à la ration stimule encore la consommation totale de matière sèche par les animaux (tabl. 3). Ainsi la quantité totale de matière sèche ingérée mesurée en gramme par $\mathrm{kg}$ de poids métabolique $\left(p^{0,75}\right)$ est augmentée de 14,5 p. Ioo par rapport à celle mesurée pour la ration marc seul et de 55,5 p. Ioo par rapport à celle mesurée pour la ration luzerne seule. 


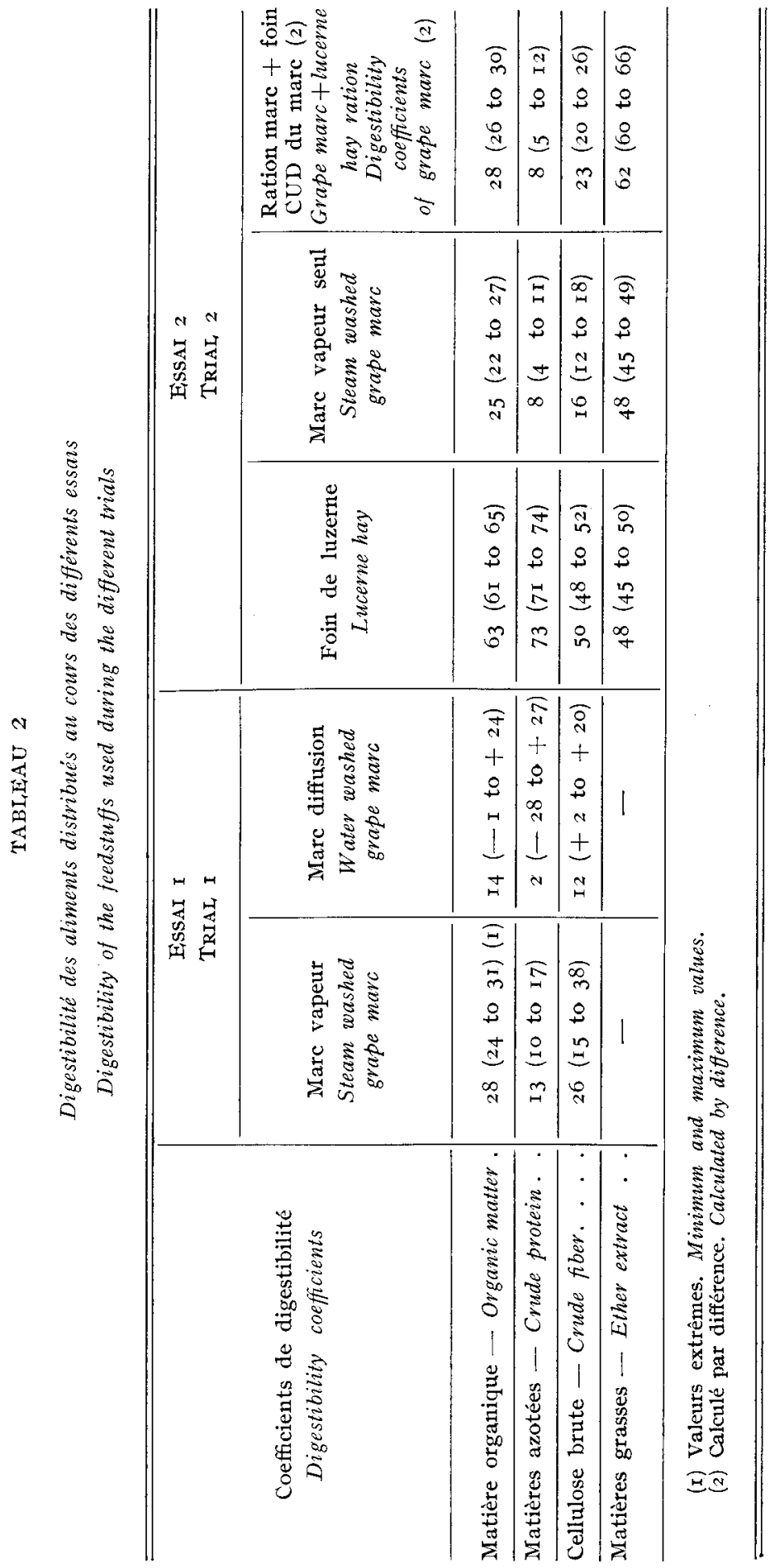




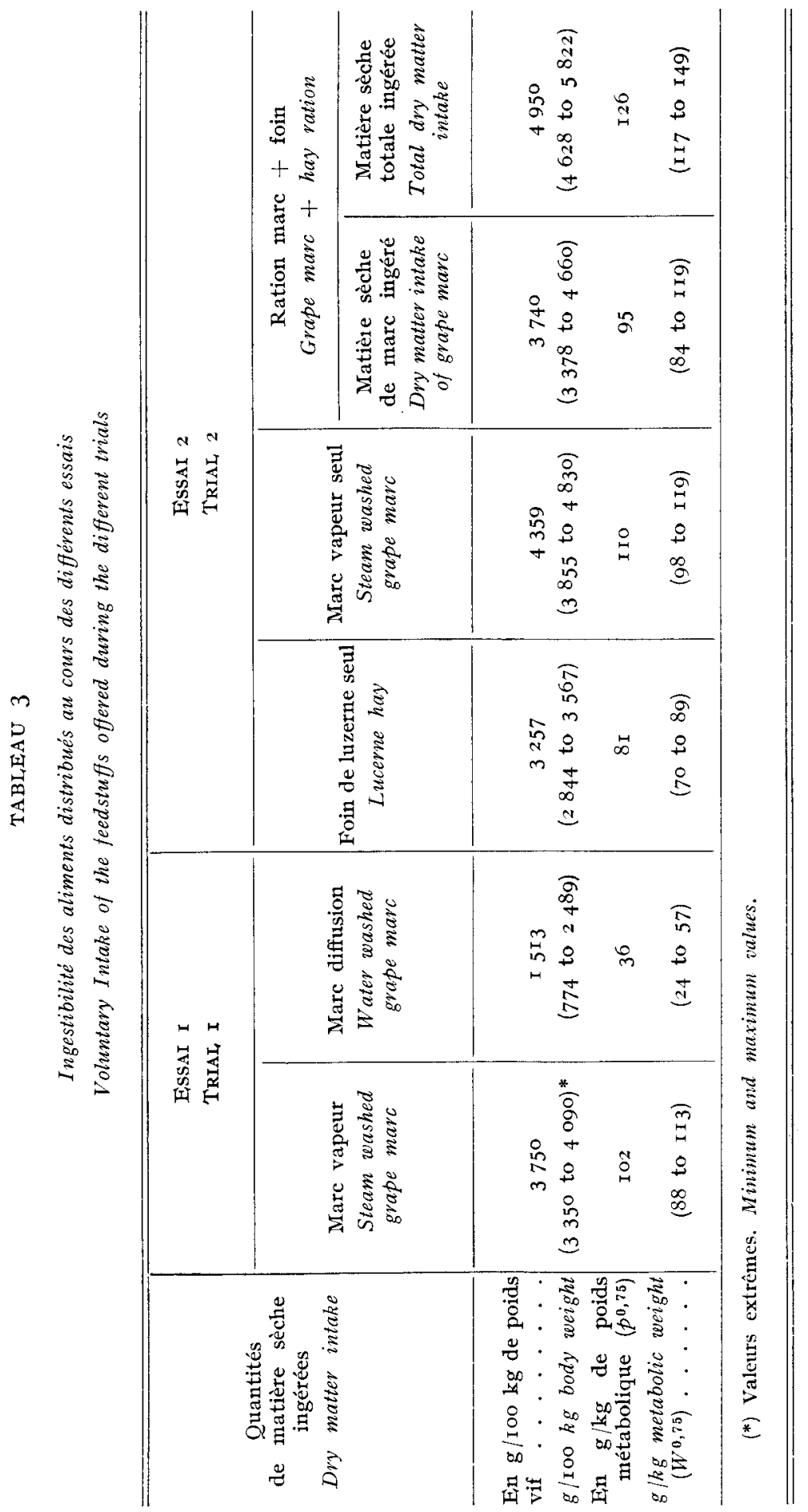




\section{Discussion}

L,es valeurs obtenues pour les coefficients de digestibilité des divers constituants du marc de raisin sont très voisines de celles signalées par d'autres auteurs pour des mares frais entiers, des mares épuisés entiers (FABRE, Igog; PICcionr, I965) ou des marcs séchés égrappés (Folger, I940; SARTI, I970; Hadjipanay IOTOU et LoUCA, I976). La très faible digestibilité de la fraction azotée du marc de raisin paraît être un phénomène analogue à celui constaté par CHARLET-LERY, LEROY et ZEITER (I955) pour les mares de pomme. Ces auteurs constatent que la. fraction azotée $\mathrm{d} u$ marc est strictement indigestible chez les moutons et les porcs et que la présence de marc dans un régime mixte semble même déprimer légèrement l'utilisation digestive de l'azote de la ration. Theriez et Boule (I970) observent le même phénomène dans leur étude de la valeur alimentaire du tourteau d'olive. Ces divers auteurs attribuent les effets observés aux tannins présents dans ces produits et qui pourraient agir de deux manières, d'une part en réduisant l'activité de la flore du rumen, d'autre part en insolubilisant les matières azotées de la ration. On peut penser à un mécanisme analogue dans le cas du marc de raisin qui est assez riche en tannins pyrocatechiques.

En ce qui concerne les quantités ingérées, les résultats obtenus confirment la meilleure appétibilité du marc vapeur par rapport au marc diffusion. Ce fait a été signalé à un degré moindre lors des essais sur ovins et bovins réalisés en station par le service interdépartemental d'élevage Languedoc-Roussillon en collaboration avec 1'ITEB et 1'ITOVIC (I976). Dans ces essais, le marc vapeur permet généralement un niveau de consommation volontaire d'environ 25 à $30 \mathrm{p}$. Ioo supérieur à celui permis par le marc diffusion. Les résultats de l'essai de digestibilité laissent supposer qu'il existe pour les mares diffusion une grande variabilité des consommations sans que l'on en connaisse pour l'instant le facteur responsable. Une analyse critique de conservation d'ensilage a été effectuée dans le cas du marc diffusion et ne permet pas de trouver une explication à cette mauvaise consommation. En effet, le $\mathrm{pH}$ et les teneurs en acides acétique, propionique, butyrique et lactique correspondent à un bon ensilage correctement conservé. La consommation du marc vapeur est par contre remarquable, qu'il soit distribué seul ou associé à du foin de luzerne. Les moutons sont capables de compenser la très faible valeur nutritive $d u$ produit par une ingestion beaucoup plus forte que dans le cas des fourrages classiques. Un tel mécanisme de compensation est en accord avec les résultats de Montgomery et Baumgardi (I965) qui montrent que les ruminants sont capables d'ajuster leur consommation de matière sèche de façon à maintenir les apports en énergie métabolisable.

Dans certains cas, il est possible, d'après les performances observées, de fixer la valeur énergétique du marc à $0,20-0,25$ UF par $\mathrm{kg}$ de matière sèche, chiffre supérieur à celui obtenu par le calcul, dans d'autres cas, la valeur alimentaire peut être nulle sans que l'on puisse pour l'instant le prévoir autrement que par un essai d'alimentation, un marc de bonne qualité étant généralement bien consommé. La teneur en matières azotées digestibles, voisine de $\mathrm{I} 7 \mathrm{~g}$ par $\mathrm{kg}$ de matière sèche pour le meilleur des mares vapeurs étudiés (valeurs extrêmes I 3 à $22 \mathrm{~g}$ ) est très faible compte tenu de la teneur relativement élevée en matières azotées totales du produit.

Enfin, si certains types de marcs peuvent constituer un aliment intéressant du fait de leur faible coût, il semble que le procédé d'épuisement par diffusion 
aboutisse parfois à des marcs mal consommés par les animaux. Il reste à connaître les causes de cette mauvaise consommation et éventuellement à trouver un moyen de l'améliorer.

Accepté pour publication en juillet 1977.

\section{Remerciements}

Nous remercions Messieurs AurejAC et BALMELle du Service interdépartemental de 1'Élevage Languedoc-Roussillon pour l'aide qu'ils nous ont apportée en nous fournissant une partie des produits utilisés.

\section{Summary \\ Nutritive value of whole grape marc silage for sheep}

Six mature "Merinos d'Arles " sheep were used to measure the intake and digestibility of the components of several types of whole grape marc silage. The steam washed grape marc was the best utilised, nevertheless, the digestibility coefficients were low: 25 to 28 per cent for organic matter, I6 to 26 per cent for crude fibre, 8 to 13 per cent for crude protein, $4^{8}$ per cent for ether extract.

The steam washed grape marc dry matter intake was high ( $\left.1 \mathrm{rog} / \mathrm{kg} \mathrm{W}^{0,75}\right)$. The contrary was true for water washed grape marc and therefore the animals lost in weight.

The addition of $600 \mathrm{~g}$ lucerne hay to the steam washed grape marc ration increased the digestibility of several components $(+7$ per cent for crude fiber and + I4 per cent for ether extract) but did not increase the digestibility of crude protein. The dry matter intake also increased by $\mathrm{I} 4.5$ per cent in relation to whole steam washed grape marc ration and 55.5 per cent to whole lucerne hay ration.

\section{Références bibliographiques}

Charlet-Lery G., Leroy A. M., Zeiter S. Z., I955. Etude chez le Mouton et le Porc de la digestibilité apparente des constituants de marcs de pomme frais, ensilés ou déshydratés. Ann. Zootech., 4, 32I-332.

DechambrF P., 1906. Les aliments du bétail. Paris. Asselin et Houzeau. p. 279-283.

DeMARQUiliY C., WEIss ph., I970. Tableaux de la valeur alimentaire des fourrages. S.E.I. Etude $n^{0} 42$.

Document ITEB-ITOVIC. Août 1976. Utilisation du marc de raisin épuisé dans l'alimentation des bovins et ovins. 4 pp., Paris.

Document du Service interdépartemental d'Élevage Languedoc-Roussillon. Juin I975. Les sousproduits végétaux disponibles pour l'alimentation des ruminants dans la région LanguedocRoussillon. p. I4-2I.

Document du Service interdépartemental d'Élevage Ianguedoc-Roussillon. I976. Eleveurs sachez utiliser le marc de raisin! $6 \mathrm{pp}$.

FABRE J., I gog. Sur la valeur alimentaire du marc de raisin. Annales de l'ENSA Montpellier., NS VIII, fasc III., 2 I9-228.

FolgER A. H., I940. The digestibility of ground prunes, winery pomace, avocado meal, asparagus butts and fenugreekmeal. Calif. Agr. Exp. Stat. Bull., 3-т I.

Hadjipanayiotou M., Louca A., I976. A note on the value of dried citrus pulp and grape marc as barley replacements in calf fattening diets. Anim. Prod., 23, 1 29-1 32.

Honcamp F., BLANCK E., I9I9. Untersuchungen über den Futterwert der Nebenprodukte und Abfälle der obst und Traubenweinbereitung - Mitteilung der Land. W. Versuchstation. Rostock. IM. 
JORE D'ARCE P., I953. Quelques observations sur 1'alimentation de secours du Mouton NordAfricain. C.R. Acad. Agric. France. I 8 février I953.

MONTGOMERY M. J., BAUMGARD'́ B. R., I965. Regulation of food intake in ruminants. I. Pelleted rations varying in energy concentration. $J$. Dairy. Sci., 48, 569-574.

Piccioni M., I965. Dictionnaive des aliments pour les animaux. Fd. agric. Bologna. p. $352-354$.

SAR'I D. M., I970. Ricerche Sulla Digeribilita, Sul valore nutritivo del marco di uva e sul valore biologica della sua sostanza proteica. Estratto dagli annali della facolta di agravia dell universita di perugia. Vol. XXV. 65-9o.

Theriez M., Bovie G., i97o. Valeur alimentaire du tourteau d'olive. Ann. Zootech., 19, I43I 57 . 